\title{
POLÍTICA DE ADMISSÃO AO GINÁSIO (1931-1945): CONTEÚDOS E FORMA REVELAM SEGMENTAÇÃO DO PRIMÁRIO
}

\author{
Geysa Spitz Alcoforado de Abreu ${ }^{\mathrm{ii}}$ \\ Universidade Estadual de Santa Catarina (UDESC) \\ Maria Angélica Pedra Minhoto ${ }^{\mathrm{iii}}$ \\ Universidade Federal de São Paulo (UNIFESP)
}

\section{RESUMO}

O objeto de estudo em análise é o exame de admissão ao ginásio, instituído em 1931, por Vargas, e utilizado por 40 anos para a seleção de alunos ao ensino secundário. A análise circunscreve-se aos anos 1931 e 1945, com o objetivo de discutir se os conteúdos e a forma do exame exerceram efeitos na conformação curricular do ensino primário paulistano. Para tanto, foram revisados estudos sobre o tema e feito um levantamento de informações acerca da realização do exame, em arquivos de cinco instituições de ensino secundário da cidade de São Paulo. Os dados foram analisados a partir dos conceitos de segmentação e de progressão, elaborados por Fritz Ringer, em obra que descreve e compara as diferentes configurações dos sistemas educacionais da Alemanha, França, Inglaterra e Estados Unidos. Os resultados indicam que o exame foi ineficiente para conter a demanda por educação secundária, infirmando parte da literatura especializada que via nessa meta a função manifesta da prova, e que sua função latente, no entanto, foi a de legitimar um padrão específico de recrutamento e camuflar a existência de barreiras institucionais e curriculares presentes no ensino elementar da época.

Palavras-chave: exame de admissão ao ginásio; ensino secundário; ensino primário; Era Vargas.

\section{THE ADMISSIONS POLICY TO THE GYM (1931-1945): CONTENT AND FORM REVEAL THE PRIMARY SEGMENTATION}

\begin{abstract}
The object of this research is the admission examination for secondary education, established in Brazil in 1931, and used during 40 years to elect pupils to gymnasium. The analysis ranges between 1931 and 1945 with the purpose of discussing whether the contents and form of the exam had effects in shaping the curriculum of primary education in Sao Paulo. Therefore, studies on the subject were reviewed and a survey about the exam in the archives of five institutions of secondary education in São Paulo was made. The data were analyzed based on the concepts of segmentation and progression, developed by Fritz Ringer, in work that describes and compares the different configurations of the educational systems of Germany, France, Britain and the United States. The results indicate that the test was ineffective to restrain the demand for secondary education, invalidating part of the literature that identified it as the manifest function of exam, and that the latent function of the exam, however, was to legitimize a particular pattern of recruitment and to mask the existence of institutional and curricular barriers present in elementary school at the time. Keywords: admission examination; secondary education; primary education; Vargas Era.
\end{abstract}




\section{Introdução}

O exame de admissão ao ginásio foi instituído, em nível nacional, no ano de 1931, e perdurou oficialmente até a promulgação da Lei $\mathrm{n}^{\circ} 5692 / 71$, quando foi instaurado o ensino obrigatório de $1^{\circ}$ grau, com duração de oito anos, integrando os cursos primário e ginásio em um único ciclo de estudos. A reforma do ensino de 1931 organizou o secundário em dois cursos seriados: o fundamental, com duração de cinco anos, e o complementar, com duração de dois anos. O complementar, geralmente oferecido em salas anexas a faculdades, era pré-requisito para a realização de matrícula nos cursos superiores. Além disso, estabeleceu como ensino secundário oficial o ministrado no Colégio Pedro II, no Distrito Federal, uma referência comum para o funcionamento de todos os outros estabelecimentos do país.

Para obter equiparação e reconhecimento do governo federal, não bastava aos ginásios espelharem o seu funcionamento no Pedro II, precisavam também passar por um rigoroso regime de inspeção oficial (cf.ABREU, 2008). Esse processo iniciava-se com a chamada inspeção preliminar, com duração mínima de dois anos, e, ao atingir uma avaliação satisfatória, o estabelecimento era elevado a outro nível de fiscalização, a chamada inspeção permanente.

No que toca ao ingresso no primeiro ano do ginásio, a reforma estabeleceu as seguintes condições: o candidato à matrícula deveria ter idade mínima de 11 anos; ser aprovado em exame de admissão com classificação suficiente (o número de vagas deveria bastar para que efetuasse a matrícula); a inscrição só poderia se realizar mediante requerimento e recibo de pagamento de taxa; a realização do exame era limitada a um único estabelecimento de ensino, onde o candidato pretendesse a matrícula.

O exame era constituído por provas escritas de Português e Aritmética, bem como provas orais, das mesmas disciplinas e de Geografia, História do Brasil e Ciências Naturais. As regras e programas eram definidos pelo Departamento Nacional de Ensino.

Ao longo dos 40 anos em que vigoraram os exames, é possível observar inúmeras alterações legais na forma, conteúdo e funcionamento para a seleção ao secundário. No entanto, nenhuma das alterações extinguiu o ritual de passagem entre os ensinos primário e secundário. Até 1952, não houve entre as exigências legais a necessidade de certificação primária para o ingresso no ginásio. É provável que esse fato, aliado ao papel seletivo do exame, tenha colaborado para justificar o diagnóstico de desarticulação entre os dois âmbitos de ensino, no Brasil, bem como a distinção do público atendido em cada uma dessas modalidades de ensino - o primário voltado à formação da camada popular e o secundário voltado às elites.

A falta de articulação entre primário e secundário é também diagnosticada pelo que se tem chamado de "dualismo" no sistema de administração pública - a repartição de competências entre os diferentes níveis de administração: o secundário, regulado e fiscalizado pela União e o primário pelos Estados.

É interessante lembrar que a fixação do exame, em âmbito nacional, ocorreu na mesma época em que a passagem pelo curso ginasial completo se transformou no único caminho de acesso ao ensino superior. O exame foi usado como instrumento oficial de seleção de indivíduos para uma opção diferenciada de inserção social. 


\section{Descompasso entre ensino secundário e sociedade brasileira na Era Vargas: perspectiva da historiografia da educação}

Não é ampla a produção de estudos acerca da história da educação nacional que versa sobre o ensino secundário, no período em que o exame de admissão vigora (1931 a 1971) e, mais especificamente, no primeiro governo de Getúlio Vargas. Alguns desses estudos apresentam distintas explicações para os fenômenos da expansão desse ensino, bem como de sua desarticulação com o primário. Em geral, se caracterizam por analisar a legislação federal e os dados oficiais e apontam o secundário como um curso eminentemente voltado aos filhos das elites e propedêutico ao ensino superior.

De acordo com Silva , por exemplo, não haveria na entrada do ginásio:

(...) um mecanismo de seleção que seria o pressuposto necessário ou a primeira exigência pedagógica de um ensino que se deveria voltar à "preparação de individualidades condutoras". Foi incontestavelmente à falta de uma verdadeira seleção dos aspirantes ao ensino secundário que este se expandiu, que proliferaram os ginásios e se multiplicaram as matrículas. A atração do ginásio, não encontrando a barreira de uma seleção adequada, não tinha, por outra parte, a compensação de uma valorização fortemente positiva do ensino primário (SILVA, 1969, p., $321)$.

Tal interpretação, bem como outras presentes ao longo da obra do autor, realiza-se à luz de uma análise histórica e de condições sócio-culturais identificadas como "modeladoras" do ensino secundário no país.

Para o andamento de sua análise, Silva utiliza-se de algumas ferramentas que merecem destaque: o autor constata um descompasso existente entre escola e sociedade devido ao dinamismo da vida social, o que acaba gerando um atraso cultural da instituição; pontua a existência de transferências culturais entre sociedades, que podem ser flagradas na educação institucionalizada; finalmente, opera com uma noção de ensino secundário contrapondo dois conceitos, o de ensino tradicional, definido como um tipo de ensino específico, caracterizado pela finalidade histórica de formar "minorias sociais" - isto é, as elites -, a partir de uma educação voltada à cultura geral, tradicionalmente identificada pelo currículo de humanidades clássicas, e que ao longo do tempo, em conseqüência da evolução social e cultural, acaba incorporando as humanidades modernas e as ciências; e o conceito de grau ou nível de ensino, significando a "educação dos adolescentes", uma etapa do processo educativo, que deve ter como função:

(...) neutralizar as influências dos fatores decorrentes da fortuna e do nascimento, a fim de que tenha êxito a formação das novas e diversificadas elites que as complexas sociedades industriais exigem. Unindo essas futuras elites, entre si, bem como aproximando-as do comum dos homens, certa educação geral dever-lhes-á ser proporcionada. Mas, esta pouco ou nada terá de comum com aquilo a que corresponde a velha noção de "cultura geral" (SILVA, 1969, p. 112).

Esses pressupostos analíticos são a chave para a compreensão das justificativas do autor acerca do crescimento do secundário e de sua desarticulação com o primário. Para Silva (1969), o secundário brasileiro foi constituído à semelhança do ensino europeu, "especialmente o francês e o alemão", ao mesmo tempo em que inexistia "um ensino elementar preparatório, estritamente vinculado às escolas secundárias, inspirado nas 
mesmas tradições", e foi esse o meio pelo qual se consolidou, "desde o nível elementar, a divisão do sistema escolar em dois ramos ou sistemas paralelos, aceitando-se na educação a segregação de classes sociais" (p. 317).

Pelas características do país - e o autor enumera as seguintes características: regime de grande propriedade agrícola, a baixa ocupação no interior, a parca concentração urbana, o legado religioso luso-católico, urbanização e industrialização tardias -, não foi possível o desenvolvimento nem de um ensino primário, e, menos ainda, de um ensino pós-primário, nos mesmos moldes dos que os da Europa.

Assim, para Silva (1969), a expansão do secundário, ao invés de representar uma extensão progressiva da escolaridade, propiciou a estagnação do primário "com a sua insuficiência quantitativa e com o empobrecimento do seu alcance e conteúdo, em vista dos quais cada vez maior se fazia seu desprestígio" (p.322). Em acréscimo a essa "defeituosa" articulação, o autor aponta para o fato de que o secundário, no período em apreço, continuou a se pautar por um "conceito acadêmico e intelectualista" - revelando as resistências das tradições e a persistência de resíduos ideológicos - não conseguindo, até aquele momento, consolidar a tendência de unificação das estruturas escolares, o que segundo ele ocorreu nos países desenvolvidos. Conclui afirmando que o secundário foi:

(...) chamado, em condições de uma expansão anômala e desordenada, a preencher uma função de educação geral e básica, [mas] nem sua estrutura e currículo lhe permitiam preenchê-la, nem a finalidade expressa a que se destinava podia ter uma concretização satisfatória. (SILVA, 1969, p.322)

Para Silva (1969), o descompasso, tanto entre a escola primária e a secundária, quanto delas em relação à sociedade brasileira, se deve às "características" peculiares do desenvolvimento econômico e social brasileiro, muito diferentes das condições presentes nos países centrais; aos transplantes culturais efetuados - além da condição de colônia, que deixou o Brasil vulnerável aos transplantes, não estavam disponíveis as "condições objetivas, resultantes das tradições gerais e pedagógicas e do desenvolvimento econômico e social, que servissem de suporte a um funcionamento eficaz e pleno das instituições" (p., 34), gerando, assim, distorções nos modelos importados; ao tratamento concedido ao secundário pelas administrações públicas, por quase toda a primeira metade do século XX, como um tipo autônomo de ensino, que teve por função o controle e a reprodução das elites dirigentes.

Do exposto, decorrem algumas considerações: Silva parece tomar o conjunto de fatos observados na história da conformação do ensino secundário no Brasil como distorções, desvios de rota, tendo em vista o padrão normativo de sua análise. $\mathrm{O}$ autor coloca em destaque aquilo que o secundário deveria ter sido, mas não alcançou, circunstância em que parece esquivar-se da oportunidade de analisar a razão pela qual essa realidade "aceitou os fatos desviantes" por ele constatados.

Ao apontar a persistência do hábito brasileiro, presente desde os tempos coloniais, de transplante e deturpação de modelos pedagógicos externos como base para o desajuste do secundário - isto é, um ensino assentado sobre inutilidades ornamentais, que não nasce de condições objetivas e nem tampouco subjetivas -, Silva parece apresentar, antes, a necessidade de definir, ou de colocar uma ordem naquele "tipo" de ensino que, como se apresenta a ele, não permite explicação lógica, parece-lhe ambíguo.

A questão dos transplantes culturais - ou da falta de autenticidade e de autonomia do Brasil no que se refere à criação de seu sistema educacional - está colocada na obra do autor como parte do problema da constituição de uma cultura nacional. A reflexão que 
realiza acerca da história da educação e da formação de sujeitos no âmbito escolar apresenta-se como possibilidade de propor e/ou viabilizar um projeto determinado de país, em face de outros modelos, usados como parâmetros para a defesa ou crítica do seu próprio projeto. Como alertado por Warde (2001, p. 4), entende-se que modelos são "constructos de um imaginário que lhes confere forma e conteúdo com um forte teor racional e um sentido prático: trata-se de ferramentas para contendas na arena política; para concorrências pelo controle do mercado; para disputas no campo educacional" e que "a idéia de uma cultura "pura', não contaminada por influências externas, é um mito" (BURKE, 1997, apud WARDE, 2001, p. 3).

Por fim, Silva identifica como expressões do avanço social a industrialização, a urbanização e o desenvolvimento científico, e constata que, apesar de o Brasil possuir certo desenvolvimento material, não apresenta condições subjetivas suficientes para ingressar plenamente no mundo desenvolvido. A solução para esse impasse parece vir da ação do Estado, o único agente com possibilidade de se afirmar como articulador de um conjunto de interesses sociais díspares, que não conseguiram se afirmar, conduzindo a sociedade à modernidade. Em outras palavras, adota como padrão analítico o Estado demiurgo, a grande força capaz de promover a necessária aceleração histórica do país em direção à modernidade. Assim, da perspectiva educacional, a solução patenteada é a criação, com expansão, de um sistema integrado de ensino, controlado pela União, que atenda a todos com o fito de formar, objetiva e subjetivamente, os indivíduos necessários a tal modernidade.

Vale lembrar o lugar e o momento no qual o autor produz essas análises: funcionário do MEC, desde 1946, Silva trabalhou no Instituto Nacional de Estudos Pedagógicos (INEP) por vários anos, ofício marcado por práticas de intervenção educacional, tanto para a elaboração, quanto para o subsídio de políticas públicas para a educação.

Com argumentação menos densa, porém similar, Nunes também revela em seu trabalho o desajuste entre o ensino secundário e a realidade brasileira, em suas palavras: "o início da quarta década do século XX marca o auge de desarticulação entre a infraestrutura e a superestrutura brasileira" (NUNES, 1999, p. 95). Localizando a expansão do secundário como conseqüência do crescimento econômico e urbano do pós-1930 no Brasil, a autora identifica como principais problemas do secundário o caráter enciclopédico dos programas ginasiais, voltados apenas à elite, única com tempo disponível para a formação de uma sólida cultura geral; a ausência de professores preparados para execução dos programas ginasiais; a falta de um curso primário que preparasse o indivíduo para o ingresso no ginásio; a inexistência de flexibilidade entre os ramos do ensino médio como impeditivo da mobilidade social que se processava no país.

Para Nunes, esses problemas educacionais tinham origem em antigas contendas e estavam marcados pela permanência de privilégios de classe - corporificados em um ensino formalista, arcaico, cujo único objetivo era a formação da elite para o ingresso no ensino superior. Situação incompatível com a nova etapa de desenvolvimento que se iniciava na vida brasileira, na qual:

(...) tornaram-se mais nítidas as classes sociais, embora a polarização só nos nossos dias [1962] comece a esboçar-se, com a burguesia industrial, o proletariado e os setores produtivos da classe média, de um lado, e a burguesia latifúndio-mercantil e os setores parasitários da classe média, de outro (NUNES, 1999, p. 95). 
O descompasso entre escola e sociedade parece, assim, tomar corpo em função do entendimento de que o processo de expansão capitalista no país ocorreu apesar das características de nossa organização social, quais sejam: no Brasil, das décadas de 1920 e 1930, ainda não havia uma burguesia industrial dinâmica capaz de impor e produzir um pensamento hegemônico, conferir à sociedade um projeto que objetivasse o progresso econômico e a conquista do poder político - tal como Nunes verifica nos países centrais. A incipiente burguesia brasileira permanece econômica e politicamente depende da oligarquia agrária - o setor tradicional da sociedade, contrário à industrialização -, não há proletariado completamente formado e a classe média é improdutiva e parasitária.

Da perspectiva adotada pela autora, refletir sobre o ensino secundário e sua expansão parece ser um exercício de esquadrinhar os vínculos e as resistências presentes na adequação do sistema educacional às exigências do crescimento econômico, sendo que a meta de desenvolvimento nacional - a superação do subdesenvolvimento brasileiro -, se apresenta como consolidação do capitalismo no país, via intensificação das atividades industriais. Essa idéia de interdependência entre educação e desenvolvimento econômico esteve na base da "ideologia nacional-desenvolvimentista" produzida pelo ISEB. Vale lembrar que Nunes estudou no Instituto, fez parte do seu quadro docente e publicou a obra em apreço na coleção Textos Pedagógicos, também do ISEB.

De acordo com Warde (2003), uma das características comuns aos trabalhos sobre o ensino secundário, produzidos ao final da década de 1960 e início de 1970, é serem "pautados nas expectativas políticas e sociais dos seus autores", quais sejam: "esperavam do ensino secundário a realização de determinadas metas sociais ou de determinados modelos educacionais". Dentre os trabalhos mencionados pela autora estão os de Nunes (1999) e Silva (1969). Nesse sentido, pode-se compreender que, ao analisarem a história da educação, os autores permanecem fiéis ao local político onde estiveram situados - fato que se revela pelo modo de representação do real, da proposta de organização da cultura nacional e de atuação dos autores, como técnicos especializados na esfera da administração pública.

As obras de Silva e Nunes, apesar de possuírem naturezas distintas e incidirem sobre várias facetas do ensino secundário, apresentam uma importante característica comum: procuram articular os problemas escolares brasileiros à totalidade social, isto é, têm em vista a compreensão da estrutura de ensino secundário tratando tanto de questões pedagógicas específicas quanto de questões extra-escolares. A partir da década de 1980, essa perspectiva comum tem perdido espaço em detrimento da realização de estudos cuja problemática é tratada de forma mais pontual (WARDE, 1993).

Dessa vertente mais recente de estudos, pode-se destacar o texto introdutório de Valente (2001) presente no Cd-rom Os exames de admissão ao Ginásio 1931 - 1969. No que se refere à legislação do exame, o autor afirma que, ao longo de sua existência, é possível observar diversas alterações realizadas quanto à forma, ao número de questões, ao cálculo da média do aluno, ao número e programas das disciplinas, à quantidade de corretores das provas, entre outras mudanças. Entretanto, pontua Valente: "o caráter fundamental do exame mantém-se: é o da seleção, da restrição do acesso à continuidade dos estudos rumo ao ensino superior". Para ele,

(...) o exame de admissão constituiu por décadas a linha divisória entre o ensino primário e a escola secundária; funcionou como um verdadeiro rito de passagem no processo de seleção à continuidade dos estudos, representado pelo ingresso no ginásio acadêmico, que teve procura intensificada a partir dos anos 1930 (VALENTE, 2001). 
Nessa mesma linha analítica, Machado (2002), investigando as provas de Matemática para a admissão ao Ginásio da Capital, considera que os exames constituíram um entrave para a proposta de modernização do ensino da referida disciplina no Brasil. Afirma que a elaboração dos exames permaneceu muito semelhante desde sua instauração até o final dos anos 1960, não retirando "das provas, em tempo algum, seu caráter seletivo pelo adestramento no fazer muitas contas" (p. 137). Além de discutir alterações nas provas de Matemática, ao longo dos 40 anos de existência do exame, o trabalho se destaca por compilar parte importante da legislação referente ao tema.

A apreensão temática do ensino, da perspectiva desses estudos, parece não ter produzido resultados abrangentes como aqueles vistos anteriormente na medida que opera um isolamento cerrado das dimensões da vida escolar. $\mathrm{O}$ foco privilegiado por Machado pouco considerou os processos de configuração de padrões escolares e pedagógicos, marcados por razões políticas, sociais e econômicas que, por exemplo, compuseram na década de 1930 as bases dos embates travados entre "católicos", "renovadores", "militares" - se não para consagrar em uníssono as posições que a historiografia insistentemente vem a eles relegando, então, para buscar apreender a finalidade central dessas disputas: a modelação do homem moderno.

\section{Repensando o descompasso entre escola e sociedade}

O descompasso entre escola e sociedade, apontado nas análises históricas e sociológicas empreendidas, parece revelar que os cursos escolares não são definidos diretamente por necessidades econômicas, ou por uma estrutura de qualificação requerida previamente. A qualificação conferida pela escola, bem como os cursos que oferece, opera com a função de converter, a médio e longo prazos, as exigências ocupacionais da administração pública, do comércio e da indústria, em qualificações educacionais. A definição dos programas do ensino secundário não ocorre apenas tendo em vista demandas econômicas específicas e imediatas - ou mesmo demandas ocupacionais -, mas a diferenciação interna e a ordenação hierárquica do sistema educacional auxiliam a tornar possível a diferenciação e a hierarquização da estrutura ocupacional.

Quando os laços entre educação secundária e desenvolvimento sócio-econômico são identificados como uma relação disfuncional ou buscam encontrar paridade entre hierarquia social e organização escolar, deixam de considerar dois aspectos fundamentais, inerentes à reordenação desse âmbito de ensino no período.

O primeiro aspecto refere-se ao sentido modernizador das reformas na Primeira República em contraste com sua organização precedente. Isso se evidencia em pontos como as disputas em torno da definição dos programas de ensino, mais ou menos voltado às humanidades clássicas ou científicas, e mesmo em torno da ampliação de alternativas de cursos pós-primários, como o normal, comercial, técnico-industrial, doméstico e artístico em outras palavras, a segmentação dos caminhos, resultante dessa tendência de modernização.

Neste ponto, faz-se necessária uma digressão acerca do conceito de segmentação. Em obra que descreve e compara as diferentes configurações dos sistemas educacionais da Alemanha, França, Inglaterra e Estados Unidos, Ringer (1979) define como sistema educacional segmentado aquele que oferece caminhos paralelos de estudos, separados por barreiras institucionais, pelo currículo e por diferenças de origem social dos estudantes.

Em relação ao ensino secundário, o autor oferece como exemplos, os colégios vocacionais ou preparatórios, nos EUA; os cursos clássicos ou modernos, na Inglaterra; os Gymnasium ou Realschule, na Alemanha. Entretanto, aponta que a especialização 
curricular, isoladamente, ou as diferenças de status entre indivíduos com tempos diferenciados de escolarização não constituem casos de segmentação.

Para Ringer, a segmentação requer simultaneamente diferenças nos currículos e na origem social. Ela pode ser vertical, isto é, apresentar compatibilidade entre hierarquia educacional e status funcional, ou pode ser horizontal, apresentar incompatibilidade entre a hierarquia educacional e a hierarquia de classe - expressa pelas distintas relações que, por exemplo, advogados e comerciantes podem manter com o sistema educacional. Aponta que o sistema segmentado tende a legitimar e a perpetuar as distâncias sociais existentes entre os diferentes estratos.

Voltando à reordenação do secundário no pós-1930, além da tendência de modernização é possível verificar, ao mesmo tempo, resistências a esse processo, algo que se expressa claramente no perfil conservador da Reforma Capanema (1942) e pelo caráter de inferioridade que vai se estendendo pelos cursos pós-primários, em face ao secundário clássico, justamente por apresentarem um perfil prático e uma orientação profissionalizante.

No jogo das pressões para reordenar o secundário, o vetor que pugna pela manutenção de um modelo de formação "tradicional" é mais marcante que o resultante das demandas funcionais decorridas do processo de industrialização e urbanização. A escola secundária, como instituição responsável por reproduzir um certo legado cultural - ou, nas palavras de Ringer (1979), como veículo de tradições - acaba desempenhando o papel de amalgamar as necessidades, valores e comportamentos típicos de uma sociedade oligárquica aos da nova era urbano-industrial.

A assimilação dos valores tradicionais, assim como a sua reconstituição, entre diferentes estratos que freqüentam o secundário se mostra eficiente para conservar hábitos que destoam dos reclamados pela sociedade moderna. Sem dúvida, esses valores não são os únicos disseminados na escola, no entanto são significativos, já que a identificação individual com as necessidades e os comportamentos ligados a um estrato social historicamente detentor de riqueza e poder, no Brasil, revela-se como estratégia de distinção, com vistas à ascensão social, daí a sua permanência na escola.

Os valores se constituem e reconstituem nas relações sociais e oferecem bases comuns para o comportamento e a compreensão dos indivíduos, isto é, fundamentam a identidade de grupos sociais e permitem a distinção daqueles que não tomam parte desse legado. Embora a escola secundária opere mais como um veículo de tradições, é preciso considerar que os valores que ali circulam não são exclusivos de uma fração social, e nem funcionam como um mecanismo intencional das elites para a consecução de suas finalidades, mas exercem efeitos recíprocos devido à interdependência entre diferentes sujeitos.

O segundo aspecto que se evidencia nesse momento é a falta de simetria entre hierarquias de classe e de status social. Não há correlação entre situação de classe - ou o lugar social dos indivíduos na ordenação capitalista - e as atribuições subjetivas de status ou o prestígio que ainda sobrevive da ordenação oligárquica. Também aqui a escola secundária acaba por desempenhar o papel de amalgamar e reconstituir as diferenças.

Além de se caracterizar como espaço de mediação entre diferentes expectativas, assentadas em valores tradicionais e modernos, o secundário faz com frequiência a intermediação entre a mudança (ou a permanência) das posições sociais entre gerações. Em um período de transformação estrutural da sociedade brasileira, com mudanças no modo produção e de estratificação social, a reprodução do legado cultural socialmente valorizado pela escola secundária se traduz em conflito, e é isso o que tem sido percebido na nossa literatura educacional como o "descompasso" entre escola e sociedade, ou como o símbolo 
das transferências e imitações culturais, que faziam do secundário um curso de "inutilidades ornamentais", fruto de um processo "postiço" de modernização.

Da mesma forma, é preciso outra digressão para esclarecer o conceito de progressão. Ringer (1979) define como sistema progressivo o que extrai das classes média e baixa uma proporção crescente de estudantes que atingem níveis educacionais mais avançados. A progressividade de um sistema pode ser definida pela comparação entre a porcentagem de acesso da população de certa faixa etária a um determinado nível educacional com a porcentagem de acesso dos diferentes estratos sociais da mesma faixa etária a esse mesmo nível educacional.

Ao tomar-se a expansão do Estado de São Paulo, desde fins do século XIX até a primeira metade do século XX, é possível notar a transformação e crescente diversificação das atividades humanas, em um processo de desenvolvimento inter-relacionado. Tal expansão engendra um processo de integração e de maior interdependência entre os grupos humanos, nunca antes observados na história local, produzindo, concomitantemente, uma disputa mais acirrada pela distribuição de poder entre os diferentes estratos sociais, chegando a atingir a própria estrutura de estratificação social.

\section{Vida escolar precedente dos ingressantes no ginásio paulistano}

Com o objetivo de verificar a trajetória escolar anterior ao ingresso no ginásio, foi realizado um levantamento de informações acerca do exame de admissão ao ginásio, na cidade de São Paulo, em arquivos de cinco instituições de ensino secundário (cf. MINHOTO, 2007). O intuito foi o de verificar se os ingressantes haviam freqüentado o ensino primário, apesar de o certificado de conclusão do primário não ser legalmente necessário à realização do exame, bem como se o curso havia preparado adequadamente os ingressantes para enfrentarem os exames.

O fato de a legislação não exigir formação primária ao ingresso no ginásio, provocou um efeito direto na seleção de documentos arquivados nos prontuários dos alunos pelas escolas. Nota-se uma freqüência baixíssima de documentação referente a esse percurso. Quatro instituições, entre as cinco pesquisadas, ofereciam na época o curso primário. A instituição que não possuía educação elementar era o único ginásio público da cidade, no entanto, como seu certificado de admissão era válido para o ingresso em qualquer ginásio do Estado, o exame ali realizado era muito concorrido, o que leva a supor que os candidatos inscritos se preparavam preliminarmente em cursos primários.

$\mathrm{Na}$ coleta das informações, houve impossibilidade de verificar o percurso escolar anterior ao ingresso no ginásio, em duas instituições da amostra - uma privada e na pública. Por isso, a seguir, estão dispostos os dados relativos a tal percurso apenas nas instituições onde foi possível fazer uma coleta consistente:

Tabela 1: Percurso escolar anterior ao exame de admissão

\begin{tabular}{rrrccc}
\hline Instituições & A & B & C & Total \\
\hline Total de matriculados & 37 & 32 & 25 & 94 \\
Primário & 32 & 22 & 18 & 72 \\
& $\%$ & 86,5 & 68,8 & 72,0 & 76,6 \\
\hline
\end{tabular}

Fonte: Tabela elaborada pelas autoras, com informações coletadas em três instituições de ensino da cidade de São Paulo.

Os dados apontam o alto índice de ingressantes com experiência no ensino primário (em média, 76,6\%), além disso, revelam que esses alunos permaneciam, no curso 
secundário, na mesma instituição de ensino que haviam freqüentado durante o primário. O último dado é significativo, pois evidencia a existência de unidade e progressividade entre os dois âmbitos de ensino, nas instituições em apreço - uma articulação que na legislação de ensino não parece existir, bem como é pouco considerada na literatura especializada.

Esse fato levou à formulação do conceito de instituição progressiva com o objetivo de qualificar as barreiras institucionais existentes no que se convencionou chamar genericamente de ensino elementar. O conceito exprime a segmentação dissimulada, no âmbito elementar de ensino, que apesar de um recrutamento cada vez mais abrangente, na época, não proporcionava eqüidade de oportunidades de escolarização, ao desenvolver mecanismos internos que restringiam a uma pequena fração da população o avanço na escolaridade.

O alto índice de continuidade entre os ensinos primário e secundário, verificado nas instituições da amostra, permite entrever que o acesso ao ginásio estava praticamente garantido de antemão àqueles que freqüentassem determinado tipo de escola primária, aquela que proporcionava desde muito cedo as condições de sucesso para a aprovação no exame de admissão.

Assim, no caminho inverso da afirmação de que a expansão do secundário não representa a extensão progressiva da escolaridade, mas propicia a estagnação do primário (SILVA, 1969), entende-se que, desde os primeiros anos da "vida escolar", há tipos distintos de escolarização, como mostraram a importância e o cuidado atribuídos pela elite e por frações das classes médias à escolha da instituição de ensino para onde enviavam seus filhos, desde muito cedo. Nota-se a valorização de um determinado caminho, ou segmento escolar, que acabava produzindo marca distintiva entre os indivíduos.

Além disso, os diferentes tipos ou segmentos de escolarização apresentam, na longa duração, tempos e movimentos de expansão igualmente distintos. De acordo com Bourdieu , em estudo dedicado a compreender as práticas culturais e as preferências de classe em termos de consumo de bens culturais, a abrangência e a progressividade dos sistemas de ensino expressam a seguinte lógica:

Quando frações de classe, que faziam pouco uso do sistema educacional, ingressam na corrida pelas qualificações acadêmicas, produzem como efeito a elevação dos investimentos educacionais nos grupos cuja reprodução era alcançada principal ou exclusivamente através da educação, uma estratégia para a manutenção da escassez relativa de suas qualificações e, conseqüentemente, de suas posições na estrutura de classe. Qualificações acadêmicas e sistema educacional, que assim os premiam, se transformam na aposta principal do jogo competitivo interclasse, o que gera o crescimento continuo e generalizado na demanda por educação e uma inflação nas qualificações acadêmicas (BOURDIEU, 2002, p. 133).

Considerando as evidências constatadas, no estudo de Bourdieu, para a compreensão da expansão e progressividade dos sistemas de ensino; considerando os dados do IBGE acerca da quantidade de estabelecimentos de ensino primário e secundário, na cidade de São Paulo - que, em 1935, possuía dez vezes mais estabelecimentos primários (587) que secundários (54); e considerando os dados apresentados por esta pesquisa acerca do alto índice de continuidade entre os ensinos primário e secundário, verificado nas instituições da amostra; pode-se concluir que a seleção dos ginasianos, na cidade de São 
Paulo, estava determinada antes mesmo do exame de admissão, ela tinha lugar no percurso preliminar do aluno.

O exame de admissão concretizou um determinado padrão de recrutamento e tinha como função, por um lado, camuflar e, por outro, legitimar a seleção realizada previamente, pois, ao que é dado a ver, a escola primária não constituía, no período, um curso único e homogêneo para todos, não ensinava os mesmos conteúdos e nem exigia os mesmos comportamentos, mas era discriminatória.

A imposição e a disseminação de programas de ensino específicos, em virtude de exames, - fato constatado em documento encontrado no colégio A, que expõe o programa de todas as séries do curso primário e que, especificamente para o último ano, reproduz fielmente os tópicos do programa para os exames de admissão - visavam à contenção do número de candidatos ao exame e ao curso secundário, o único caminho que conduzia aos cursos superiores, ou a posições de destaque, e operavam a monopolização dessas posições em favor dos detentores de certificados escolares.

Por esse motivo, pode-se compreender que a mera ampliação da rede de ensino elementar - empreendida principalmente pela ação do governo estadual naquela época não conduzia às mesmas possibilidades de acesso aos graus mais altos de escolarização àqueles que dela tomavam parte, mas acabava reforçando a própria seletividade que desejava ocultar, já que, pela análise dos dados, foi principalmente pelo atendimento diferenciado aos estabelecimentos de ensino primário existentes na cidade que se operou a cisão e a definição dos percursos escolares futuros dos alunos - o ensino primário paulistano mostrou-se heterogêneo, segmentado, pois oferecia cursos paralelos de estudos, separados por barreiras institucionais, pelo currículo e muito provavelmente por diferenças de origem social dos estudantes.

Tomando como plataforma de análise a vida escolar prévia dos aprovados em exames de admissão, o estudo permitiu apontar que a barreira entre os ensinos primário e secundário era transposta com frequiência e com facilidade por indivíduos que apresentavam percursos escolares comuns: eles freqüentavam o curso elementar na mesma instituição de ensino em que ingressavam no ginásio. O papel do exame era o de legitimar esse padrão de recrutamento e, ao mesmo tempo, ajudar a camuflar a existência de barreiras institucionais no ensino elementar.

A questão básica que a análise indicou e que precisa ser aprofundada em novas pesquisas é a de que se deve pensar, já no ensino elementar, não apenas em uma segmentação vertical do sistema educativo - a mais típica e evidente distinção da trilha educacional que conduz os estudantes a níveis mais elevados, principalmente para uma clientela que detinha posições sociais de destaque na hierarquia social. Deve-se pensar, também, em uma segmentação horizontal, algo que parece ter se processado na cidade de São Paulo da seguinte maneira: enquanto frações das classes médias e da elite paulistana frequientavam escolas progressivas privadas já no curso elementar, crianças também das classes médias e de classes menos favorecidas, quando chegavam à escola, ingressavam na rede de ensino pelas portas dos grupos escolares públicos, instituições que ofereciam menor potencial de acesso à educação secundária.

\section{Referências}

ABREU, Geysa S. A. de. A homogeneização do ensino secundário na década de 1930: estratégias de eficiência, racionalidade e controle. Educar em Revista, Curitiba, $\mathrm{n}^{\circ} 2$, 2010. Disponível em: http://www.scielo.br/scielo.php?script=sci_arttext\&pid=S0104$40602010000500018 \& \operatorname{lng}=$ pt\&nrm=iso. Acesso em: 30 set. 2011. 
BRASIL. Decreto-Lei no 5.692, de 11 de Agosto de 1971. Fixa Diretrizes e Bases para o

Ensino de $1^{\circ}$ e $2^{\circ}$ graus e dá outras providências. Disponível em: http://www.planalto.gov.br/ccivil_03/leis/L5692.htm. Acesso em: 30 set. 2011.

BOURDIEU, P. Distinction: a social critique of the judgement of taste. Cambridge: Harvard, 2002.

MACHADO. Rita G. Uma Análise dos Exames de Admissão ao Secundário (19301970): subsídios para a História da Educação Matemática. Dissertação (Mestrado em Educação Matemática) - Pontifícia Universidade Católica de São Paulo, 2002.

MINHOTO, M. A. P. Da Progressão do Ensino Elementar ao Ensino Secundário (1931-1945): crítica do exame de admissão ao ginásio. Tese (Doutorado em Educação) Pontifícia Universidade Católica de São Paulo, 2007.

NUNES, Maria Thetis. Ensino secundário e sociedade brasileira. $2^{\mathrm{a}}$ ed., revisada e ampliada, Sergipe: UFS, 1999.

RINGER, Fritz K. Education and society in modern Europe. Indiana University Press: USA, 1979.

SILVA, Geraldo Bastos. A educação secundária: perspectiva histórica e teoria. São Paulo: Ed. Nacional, 1969.

VALENTE, W. Exames e provas como fontes para História da Educação. In: VALENTE, W. (Coord.). Os exames de admissão ao Ginásio 1931-1969. Arquivos da Escola Estadual de São Paulo. São Paulo. 3 Cd-Rom, 2001.

WARDE, M. J. A produção discente nos programas de pós-graduação em Educação no Brasil (1982-1991): avaliação e perspectivas. In: Avaliação e perspectivas na área da educação (1982-1991). ANPEd/CNPq, Porto Alegre, set., pp. 51-90, 1993.

Americanismo e educação: a fabricação do “homem novo". Subprojeto: Tecnologias de estado e instauração de sistemas. São Paulo: convênio Capes/Procad, 2001.

Internacionalização-Nacionalização de padrões pedagógicos e escolares do ensino secundário e profissional: projeto de pesquisa. Pontifícia Universidade Católica de São Paulo, São Paulo, 2003.

\footnotetext{
${ }^{\text {i }}$ Pesquisa financiada pelo CNPq.

ii Professora Adjunta do Centro de Ciências Humanas e da Educação (FAED) da Universidade do Estado de Santa Catarina. E-mail: geysa.abreu@uol.com.br

iii Professora Adjunta da Escola de Filosofia, Letras e Ciências Humanas (EFLCH) da Universidade Federal de São Paulo - Campus Guarulhos, Curso de Pedagogia. E-mail: mminhoto@unifesp.br
}

Recebido em abril de 2011

Aprovado em junho de 2011 